\title{
Gambaran Luka pada Kecelakaan Lalu Lintas Khususnya Pengendara Kendaraan Roda Dua yang Tidak Memakai Helm
}

\author{
Richard D. Lintang, ${ }^{1}$ Johannis F. Mallo, ${ }^{2}$ Djemi Tomuka ${ }^{2}$
}

${ }^{1}$ Program Studi Pendidikan Dokter Fakultas Kedokteran Universitas Sam Ratulangi, Manado, Sulawesi Utara, Indonesia

${ }^{2}$ Bagian Ilmu Kedokteran Forensik dan Medikolegal Fakultas Kedokteran Universitas Sam Ratulangi, Manado, Sulawesi Utara, Indonesia

Email: richard.richardlintang.lintang@gmail.com

\begin{abstract}
According to WHO data, the Global status report on road safety 2018, Indonesia in 2018 , with a population of $261,115,456$ people reported 31,282 deaths due to traffic accidents, with an estimated mortality rate of 12.2 per 100,000 people. From the number of deaths, $73.6 \%$ were two-wheeled-vehicle riders. It is also stated in this report that even though Indonesia has implemented regulations regarding the need to wear head protection while riding, it is estimated that only $71 \%$ wear helmets. This study was aimed to obtain the description of injuries that occurred among two-wheeled-vehicle riders who had traffic accidents with and without wearing helmets. The results showed that the wound description of two-wheeled riders who did not wear helmets was not much different from the riders who wore helmets when they had traffic accidents, however, it could be differed from the severity of the injuries. In conclusion, there was a difference in wound description of traffic accidents between two-wheeled drivers with and without wearing helmets.
\end{abstract}

Keywords: wound, traffic accident, two-wheeled riders, helmet

\begin{abstract}
Abstrak: Menurut data WHO "Global status report on road safety 2018", pada tahun 2018, Indonesia dengan populasi 261.115.456 penduduk dilaporkan mengalami 31.282 jumlah kematian akibat kecelakaan lalu lintas, dengan estimasi angka kematian 12,2 per 100.000 orang. Dari jumlah kejadian kematian tersebut, 73,6\% ialah pengendara kendaraan roda dua. Dikatakan juga bahwa dari semua pengendara tersebut, walaupun Indonesia telah menerapkan peraturan akan keperluan memakai alat pelindung kepala selagi berlalu lintas, terestimasi hanya $71 \%$ yang memakai helm. Penelitian ini bertujuan untuk mendapatkan gambaran luka pada kecelakaan lalu lintas khususnya pengendara kendaraan roda dua yang tidak memakai helm. Jenis penelitian ialah literature review, menggunakan data yang diperoleh dari database Pubmed, Clinical Key, dan Google Scholar. Hasil penelitian mendapatkan 10 literatur yang memenuhi kriteria inklusi dan eksklusi serta lolos tahap seleksi dari 1.321 literatur. Gambaran luka yang didapat pada pengendara roda dua yang tidak dan yang memakai helm saat mengalami kecelakaan lalu lintas dapat dibedakan dengan melihat tingkat keparahan dari luka dan cedera yang dialami oleh pengendara tersebut. Simpulan penelitian ini ialah terdapat perbedaan gambaran luka akibat kecelakaan pada pengendara roda dua yang memakai helm dan yang tidak memakai helm.
\end{abstract}

Kata kunci: luka, kecelakaan lalu lintas, pengendara roda dua, helm

\section{PENDAHULUAN}

Data "Global status report on road safety 2018" oleh WHO pada tabel berjudul "Road traffic deaths and proportion of road users by country/area", melaporkan bahwa pada tahun 2018, Indonesia dengan populasi 261.115.456 penduduk mengalami 31.282 jumlah kejadian kematian akibat kecelakaan lalu lintas (KLL), dengan estimasi angka kematian 12,2 per 100.000 orang. Dari 
jumlah kejadian kematian tersebut, $73,6 \%$ ialah pengendara kendaraan roda dua. Dalam laporan ini juga disebutkan bahwa walaupun Indonesia telah menerapkan peraturan akan keperluan memakai alat pelindung kepala selagi berlalu lintas, terestimasi hanya $71 \%$ pengendara kendaran roda dua yang memakai helm. ${ }^{1}$

Data terbaru dari Kementerian Komunikasi dan Informatika menunjukkan bahwa rata-rata 3 orang meninggal setiap jam akibat kecelakaan jalan. Data tersebut juga menyatakan bahwa besarnya jumlah kecelakaan tersebut disebabkan oleh beberapa hal, yaitu $61 \%$ kecelakaan disebabkan oleh faktor manusia yaitu terkait dengan kemampuan serta karakter pengemudi, 9\% disebabkan karena faktor kendaraan (terkait dengan pemenuhan persyaratan teknik laik jalan), dan $30 \%$ disebabkan oleh faktor prasarana dan lingkungan. ${ }^{2}$ Berdasarkan data dari Polri, terjadi 107.500 kecelakaan lalu lintas pada taun 2019. Angka ini meningkat 3\% dari 2018, yaitu sebanyak 103.672 kecelakaan, namun, jumlah korban meninggal pada 2019 menurun sebesar 6\% menjadi sebanyak 23.530 orang sedangkan pada 2018 yaitu berjumlah 27.910 jiwa. $^{3}$

Trauma pada kepala merupakan penyebab kematian terbesar untuk pengendara kendaraan roda dua. ${ }^{4}$ Pemakaian helm yang tepat dapat mengurangi risiko terjadinya trauma kepala sebanyak $69 \%$, dan terjadinya trauma yang bersifat fatal sebanyak $42 \% .{ }^{5,6}$

Berdasarkan beberapa literatur diasumsikan bahwa terdapat perbedaan gambaran luka pada pengendara yang mengalami kecelakaan sambil memakai helm dan yang tidak memakai helm. Oleh karena itu penulis tertarik untuk menelusuri lebih lanjut mengenai perbedaan jenis luka kecelakaan pada pengendara yang memakai helm dan yang tidak memakai helm saat kecelakaan terjadi mengingat masih tingginya angka pengendara yang tidak memakai helm dan rawannya terjadi kecelakaan dewasa ini.

\section{METODE PENELITIAN}

Penelitian yang dilakukan ialah suatu literature review. Pencarian data menggunakan tiga database dengan kriteria yang ditentukan yaitu Pubmed, Clinical Key, dan Google Scholar. Kata kunci dalam pencarian artikel yaitu Motorcylce, Injury, dan Helmet dan Gambaran Luka, Motor, dan Helm. Penelusuran jurnal publikasi dilakukan pada ketiga database dengan menggunakan kata kunci yang telah dipilih. Artikel atau jurnal yang sesuai dengan kriteria inklusi dan eksklusi diambil untuk selanjutnya dianalisis. Penelitian ini menggunakan literatur terbitan yang dapat diakses fulltext dalam format pdf. Kriteria jurnal yang dikaji ialah artikel jurnal penelitian berbahasa Indonesia atau Inggris, atau gabungan keduanya.

\section{HASIL PENELITIAN}

Berdasarkan pencarian literatur melalui database elektronik Pubmed, Clinical Key dan Google Scholar diperoleh sebanyak 98 artikel menggunakan Pubmed, 548 artikel menggunakan Clinical Key, dan 681 artikel menggunakan Google Scholar, dengan total artikel berjumlah 1.321 artikel $(\mathrm{n}=1.321)$. Setelah dilakukan pencarian sesuai dengan kriteria inklusi dan eksklusi, kemudian dilakukan eksklusi bila artikel tidak dapat diakses dalam bentuk fulltext. Hasil seleksi akhir didapatkan 10 literatur yang memenuhi kriteria dan lolos tahap seleksi. Tabel 1 memperlihatkan 10 literatur tersebut disertai keterangan mengenai penulis, tahun penulisan, judul, dan hasil penelitian.

Tabel 1. Hasil analisis 10 literatur yang digunakan dalam penelitian

\begin{tabular}{|c|c|c|}
\hline $\begin{array}{l}\text { Penulis, } \\
\text { tahun }\end{array}$ & Judul & Hasil Penelitian \\
\hline $\begin{array}{l}\text { Park G et al, } \\
2019^{5}\end{array}$ & $\begin{array}{l}\text { Protective effect of helmet } \\
\text { use on cervical injury in } \\
\text { motorcycle crashes: a }\end{array}$ & $\begin{array}{l}2.600 \text { pasien dianalisa, } 1.145(44 \%) \text { menggunakan helm saat } \\
\text { kecelakaan. Kelompok pasien yang tidak memakai helm saat } \\
\text { kecelakaan lebih banyak memperlihatkan status mental yang buruk, }\end{array}$ \\
\hline
\end{tabular}


case-control study

Patel P et al, Unhelmeted Motorcycle $2019^{7}$

Ninh TH et al, $2018^{8}$

Siddiqui $\mathrm{S}$ et Patterns of injury among al, $2016^{9}$

Kawengian $\mathrm{F}$ et al, $2017^{10}$

Lopes Albuquerque et al, $2014^{11}$

Liu C, $2012^{12}$
Changes in motorcyclerelated injuries and deaths after mandatory motorcycle helmet law in a district of Vietnam motorized two-wheeler pillion riders in New

Hubungan penggunaan helm dengan derajat cedera kepala akibat kecelakaan lalu lintas darat di RSUP Prof. Dr. R. D. Kandou Manado dan RS. Bhayangkara Tk. III Manado

How safe is your motorcycle helmet? Delhi, India tingkat cedera yang lebih tinggi (kepala, muka, leher, dan dada), resiko cedera otak yang lebih tinggi, dan resiko cedera tulang belakang servikal yang lebih tinggi (semua $\mathrm{p}<0,01$ ).

Tingkat mortalitas kelompok yang tidak memakai helm pun lebih tinggi dari kelompok yang memakai helm.

Pada tahun 2013, data NTDB menunjukkan adanya 10.345 kecelakaan sepeda motor di Amerika Serikat, dimana 6.250 memakai helm saat kecelakaan, dan 4.095 tidak memakai helm saat kecelakaan. Kelompok yang tidak memakai helm datang ke Unit Trauma dengan rerata GCS yang lebih rendah $(13 \pm 3,9)$ dari kelompok yang memakai helm $(14 \pm 3,9)(\mathrm{p}<0,01)$.

Yang tidak memakai helm juga datang dengan ISS yang lebih tinggi $(13 \pm 10,8)$ dibandingkan dengan yang memakai helm $(12 \pm 9,9)$ $(\mathrm{p}<0,01)$.

Penelitian ini membandingkan jumlah kasus kejadian cedera kepala dan kematian pengendara sepeda motor sebelum dan sesudah adanya peraturan yang menharuskan penggunaan helm.

Ditemukan bahwa dibandingkan dengan jaman sebelum peraturan, kejadian cedera akibat kejadian terkait dengan sepeda motor $(\mathrm{RR}=$ $0,53)$, cedera kepala $(R R=0,35)$, cedera kepala berat $(R R=0,47)$, dan kematian $(R R=0,69)$ menurun drastis pada jaman setelah peraturan.

Penelitian mengambil data dari 466 kasus cedera yang dialami penumpang sepeda motor akibat kecelakaan lalu lintas, dan terdapat 108 laki-laki memakai helm, 161 laki-laki tidak memakai helm, 3 perempuan memakai helm, dan 194 perempuan tidak memakai helm.

Penumpang yang tidak memakai helm, baik laki-laki maupun perempuan, datang dengan GCS yang jauh lebih rendah dari yang memakai helm. (12,6 dan 12,8 dibandingkan dengan 13,8 dan 15) $(\mathrm{p}=0,04)$ dan dengan resiko yang lebih tinggi mendapat cedera kepala dan leher $(53,4 \%$ dibandingkan $27,8 \%)(\mathrm{p}<0,01)$.

Dari 137 responden paling banyak tidak menggunakan helm dan mengalami cedera kepala sedang yaitu berjumlah 54 responden $(39,4 \%)$, paling sedikit pada responden yang menggunakan helm berstandar dan mengalami cedera kepala sedang dan berat yaitu masing-masing 4 responden (2,9\%). Selanjutnya dari 137 responden, paling banyak mengalami cedera kepala ringan yaitu 67 responden $(48,9 \%)$ dan responden paling sedikit mengalami cedera kepala berat yaitu berjumlah 12 responden $(8.8 \%)$.

Setelah dilakukan Uji Spearman's rho, diperoleh nilai P value (2tailed) adalah $0.017<0.05$.

Penelitian ini berkonklusi bahwa H0 ditolak, yang berarti ada hubungan penggunaan helm dengan derajat cedera kepala akibat kecelakaan lalu lintas darat di RSUP Prof. Dr. R. D. Kandou Manado.

Rekam medis dari 253 pengendara roda dua dianalisa oleh penelitian ini, dimana 156 tidak memakai helm, 51 memakai helm open-face, dan 46 memakai helm full-face.

Perbandingan FISS menandakan yang tidak memakai helm dan memakai helm open-face mengalami cedera maksilofasial yang lebih berat dibandingkan dengan yang memakai full-face. Tingkat kejadian cedera otak lebih tinggi pada yang tidak memakai helm dan yang memakai open-face.

Penelitian ini memisahkan total 127 pasien dalam 4 kelompok. Kelompok 1 memakai full-face, kelompok 2 memakai open-face, kelompok 3 memakai half-face, dan kelompok 4 tidak memakai helm. 

kelompok 1 adalah $0.29 \pm 0.48$, kelompok 2 adalah $0.88 \pm 1.41$, kelompok 3 adalah 1.23 \pm 1.59 , dan kelompok 4 adalah 1.78 \pm 1.92 . Penelitian ini berkonklusi bahwa semakin kurang proteksi yang diberikan oleh jenis helm tertentu, maka semakin berat cedera dan resiko cedera terhadap muka dan kepala, seperti fraktur tulang muka dan perdarahan intracranial.

$\mathrm{Yu} \mathrm{W}$ et al, Effectiveness of different $2011^{13} \quad$ types of motorcycle helmets and effects of their improper use on head injuries

Kaltman $\mathrm{J}$ et 7-Year retrospective evaal, 2010 luation of craniofacial fractures in helmeted vs. non-helmeted motorcycle crashes in Broward County, Florida ${ }^{14}$

Evans $\mathrm{MB}$ et 5 year retrospective al, $2008^{15} \quad$ evaluation of helmeted $v$ s. non helmeted motorcycle crashes and facial injuries sustained at a level 1 trauma center
Analisis penelitian ini membandingkan pengendara sepeda motor yang menggunakan helm dan yang tidak memakai helm dan menemukan bahwa pengendara yang tidak memakai helm 4 kali lebih beresiko mengalami cedera kepala $($ Odds Ratio=4,54) dan 10 kali lebih beresiko mengalami cedera otak. (Odds Ratio= 10,4).

Dari 1.734 pasien yang mengalami kecelakaan lalu lintas saat mengendarai sepeda motor, ditemukan 520 pasien yang memakai helm, dan 1.214 tidak memakai helm.

Penelitian ini menemukan GCS rerata pemakai helm ialah 11,8 dan 12,09 bagi yang tidak memakai helm. Nilai AIS rata-rata pemakai helm1,6 dan 3,13 bagi yang tidak memakai helm. Sebanyak 81 kasus kematian terjadi di antara yang memakai helm sedangkan pada yang tidak memakai helm terjadi 150 kasus kematian.

Selain itu, terdapat 292 kasus fraktur tulang muka dan 173 fraktur tengkorak pada yang tidak memakai helm, sedangkan pada yang memakai helm terdapat 92 kasus fraktur tulang muka dan 37 kasus fraktur tengkorak. Terdapat juga 155 kasus cedera intrakranial pada yang memakai helm dan 241 kasus cedera intrakranial pada yang tidak memakai helm.

Dari 631 pasien yang mengalami kecelakaan lalu lintas saat mengendarai sepeda motor, 336 pasien memakai helm dan 295 tidak memakai helm.

Penelitian ini menemukan GCS rata-rata pemakai helm ialah 12,7 dan 11,4 bagi yang tidak memakai helm. 16 kematian terjadi pada kelompok yang memakai helm, sedangkan 21 kematian terjadi pada kelompok yang tidak memakai helm.

Kelompok yang memakai helm juga terdapat 55 kasus fraktur tulang muka, sedangkan yang tidak memakai helm terdapat 93 kasus fraktur setipe. Terjadi 73 luka terbuka di muka bagi yang memakai helm dan 175 luka terbuka di muka bagi yang tidak memakai helm. Terakhir, didapatkan adanya 106 kasus cedera intrakranial bagi yang memakai helm dan 138 kasus cedera intrakranial bagi yang tidak memakai helm.

\section{BAHASAN}

Hasil kajian literatur mendapatkan bahwa gambaran luka pada pengendara roda dua yang tidak memakai helm saat mengalami KLL tidak berbeda jauh dengan yang ditemukan pada pengendara yang memakai helm, namun dapat dibedakan dengan melihat tingkat keparahan luka dan cedera yang dialami oleh pengendara tersebut.

Secara umum, literatur yang diperoleh menyatakan bahwa pengendara yang tidak memakai helm mengalami cedera kepala dan muka yang lebih berat dibandingkan dengan yang memakai helm saat terjadi
KLL. Hal ini ditandakan dengan status mental yang lebih buruk pada yang tidak memakai helm dibandingkan dengan yang memakai helm dan dibuktikan dengan rerata nilai GCS pada pengendara yang tidak memakai helm biasanya lebih rendah daripada yang memakai helm. Hasil ini didukung oleh penelitian oleh Kawengian et $\mathrm{al}^{10}$ di Manado dan penelitian $\mathrm{Liu}^{12} \mathrm{di}$ Taiwan dengan simpulan bahwa terdapat hubungan antara pelindung kepala (helm) dan tingkat keparahan cedera yang dialami pengendara sepeda motor, dan cedera (serta dengan risiko terjadi cedera tersebut) akan 
semakin berat dengan berkurangnya pelindung kepala (dari full-face ke openface ke yang tidak memakai helm sama sekali).

Selain perbedaan keparahan cedera yang dialami, literatur yang didapatkan juga menandakan adanya peningkatan insidens dan risiko terjadinya cedera pada kepala, muka, intrakranial, dan tulang belakang servikal. Mortalitas juga meningkat pada pengendara roda dua yang tidak memakai helm.

Namun, penting diperhatikan bahwa terdapat dua penelitian evaluasi retrospektif selama 7 tahun oleh Kaltman et $\mathrm{al}^{14}$ di Florida dan oleh Evans et al ${ }^{15}$ di Pusat Trauma Tingkat 1 selama 5 tahun yang menunjukkan hal yang sama mengenai meningkatnya mortalitas pada yang tidak memakai helm serta meningkatnya insidens terjadi cedera pada tulang muka, tengkorak, dan intrakranial. Namun kedua penelitian ini berbeda dengan literatur lain mengenai GCS rerata pasien, yaitu kedua literatur ini mendapatkan bahwa yang tidak memakai helm datang dengan GCS rerata lebih tinggi daripada yang memakai helm.

\section{SIMPULAN}

Gambaran luka pada pengendara kendaraan roda dua yang tidak memakai helm saat mengalami kecelakaan lalu lintas dapat dibedakan dengan yang memakai helm dilihat dari tingkat keparahan luka dan cedera yang dialami pengendara tersebut.

\section{Konflik Kepentingan}

Penulis menyatakan tidak terdapat konflik kepentingan dalam studi ini.

\section{DAFTAR PUSTAKA}

1. WHO Global status report on road safety 2018. WHO. Published online 2020. [cited 2020 Sep 16]. Available from: http://www.who.int/violence_injury_pr evention/road_safety_status/2018/en/

2. Kementerian Komunikasi dan Informatika. Rata-rata Tiga Orang Meninggal Setiap Jam Akibat Kecelakaan Jalan. Artikel GPR. [cited 2020 Sep 16]. Available from: https://kominfo.go.id/index.php/content /detail/10368/rata-rata-tiga-orangmeninggal-setiap-jam-akibatkecelakaan-jalan/0/artikel_gpr

3. Akbar N. Jumlah Kecelakaan Lalu Lintas Naik 3 Persen pada 2019 . Republika Online. [cited 2020 Sep 20].Available from: https://nasional.republika.co.id/berita/q 37i3n423/jumlah-kecelakaan-lalu-lintas -naik-3-persen-pada-2019

4. Sadeghi-Bazargani H, Samadirad B, Hosseinpour-Feizi $\mathrm{H}$. Epidemiology of traffic fatalities among motorcycle users in East Azerbaijan, Iran. Biomed Res Int. 2018;2018. Doi:10.1155/2018/6971904

5. Park GJ, Shin J, Kim SC, Na DS, Lee HJ, KimH, et al. Protective effect of helmet use on cervical injury in motorcycle crashes: a case-control study. Injury. 2019;50(3): 657-662. Doi:10.1016/j.injury.2019.01. 030

6. Liu BC, Ivers R, Norton R, Boufous S, Blows S, Lo SK. Helmets for preventing injury in motorcycle riders. Cochrane Database Syst Rev. 2008;(1). Doi:10.1002/ 14651858. CD004333.pub3

7. Patel PB, Staley CA, Mehta S, Schenker ML. Unhelmeted motorcycle riders have increased injury burden: a need to revisit universal helmet laws. J Surg Res. 2019;242:177-82. Doi:10.1016/j.jss. 2019.03.023

8. Xiaodan M, LaMonte MJ, Hovey KM, Freudenheim JL, Andrews CA, Genco $\mathrm{RJ}$, et al. Changes in motorcycle-related injuries and deaths after mandatory motorcycle helmet law in a district of Vietnam. Physiol Behav. 2018;176(12): 139-148. Doi:10.1080/15389588.2017. 1322203. Changes

9. Siddiqui SM, Sagar S, Misra MC, Gupta A, Crandall M, Swaroop M. Patterns of injury among motorized two-wheeler pillion riders in New Delhi, India. J Surg Res. 2016;205(1):142-146. Doi:10. 1016/j.jss.2016.06.033

10. Kawengian F, Mulyadi, Malara R. Hubungan penggunaan helm dengan derajat cedera kepala akibat kecelakaan lalu lintas darat di RSUP Prof. Dr. R. D. Kandou Manado dan RS Bhayangkara Tk. III Manado. eJournal Keperawatan. 2017; 5:1-7.

11. Lopes Albuquerque CE, Arcanjo FPN, Cristino-Filho G, Mont'alverne Lopes- 
Filho A, de Almeida CP, et al. How safe is your motorcycle helmet? J Oral Maxillofac Surg. 2014;72(3):542-9.

12. Liu CH. 104 The injury severity of the face, head and neck of motorcyclists in different types of helmets during motor vehicle accidents. Ann Emerg Med. 2012;60(4):S38. annemergmed.2012.06.081

13. Yu WY, Chen CY, Chiu WT, Lin MR. Effectiveness of different types of motorcycle helmets and effects of their improper use on head injuries. Int $\mathbf{J}$ Epidemiol. 2011;40(3):794-803. Doi:10. 1093/ije/dyr040
14. Kaltman JM, Puente I, Carrillo E, Kaltman SI. 7-year retrospective evaluation of craniofacial fractures in helmeted vs. non-helmeted motorcycle crashes in Broward County, Florida. Oral Surg Oral Med Oral Pathol Oral Radiol Endod. 2010;110(3):316-7. Doi:10.101 6/j.tripleo.2010.05.026

15. Evans B, Kaltman S, Parra MW, Puente I. 5 year retrospective evaluation of helmeted vs. non helmeted motorcycle crashes and facial injuries sustained at a level 1 trauma center. Oral Surg Oral Med Oral Pathol Oral Radiol Endod. 2008;106(4):507-8. 